\title{
Association between normalized lactate load and mortality in patients with septic shock: an analysis of the MIMIC-III database
}

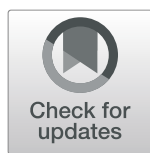

Han Chen, Shu-Rong Gong and Rong-Guo Yu*

\begin{abstract}
Background: An index of dynamic lactate change that incorporates both the magnitude of change and the time interval of such change, termed "normalized lactate load," may reflect the hypoxic burden of septic shock. We aimed to evaluate the association between normalized lactate load and 28-day mortality in adult septic shock patients.

Methods: Patients with septic shock were identified from the Medical Information Mart for Intensive Care (MIMIC)III database. Lactate load was defined as the sum of the area under the curve (AUC) of serial lactate levels using the trapezoidal rule, and normalized lactate load was defined as the lactate load divided by time. Receiver-operating characteristic curves were constructed to determine the performance of initial lactate, maximum lactate and normalized lactate load in predicting 28-day mortality.

Results: A total of 1371 septic shock patients were included, and the 28-day mortality was $39.8 \%$. Non-survivors had significantly higher initial lactate (means \pm standard deviations: $3.9 \pm 2.9$ vs. $2.8 \pm 1.7 \mathrm{mmol} / \mathrm{L}$ ), maximum lactate $(5.8 \pm 3.8$ vs. $4.3 \pm 2.2 \mathrm{mmol} / \mathrm{L})$, lactate load $(94.3 \pm 71.8 \mathrm{vs} .61 .1 \pm 36.4 \mathrm{mmol} \cdot \mathrm{hr} . / \mathrm{L})$ and normalized lactate load $(3.9 \pm$ 3.0 vs. $2.5 \pm 1.5 \mathrm{mmol} / \mathrm{L}$, all $p<0.001)$. The AUCs of initial lactate, maximum lactate and normalized lactate load were 0.623 (95\% confidence interval: $0.596-0.648$, with a cut-off value of $4.4 \mathrm{mmol} / \mathrm{L}), 0.606(0.580-0.632$, with a cutoff value of $2.6 \mathrm{mmol} / \mathrm{L})$ and $0.681(0.656-0.706$, with a cut-off value of $2.6 \mathrm{mmol} / \mathrm{L})$, respectively. The AUC of normalized lactate load was significantly greater than both initial lactate and maximum lactate (all $p<0.001$ ). In the multivariate logistic regression model, normalized lactate load was identified as an independent risk factor for 28day mortality.
\end{abstract}

Conclusions: Normalized lactate load is an independent risk factor for 28-day mortality in adult septic shock patients. Normalized lactate load had better accuracy than both initial and maximum lactate in determining the prognosis of septic shock patients.

Keywords: Septic shock, Lactate, MIMIC-III, Mortality

\footnotetext{
*Correspondence: garyyrg@126.com; garyyrg@yahoo.com

Surgical Intensive Care Unit, Fujian Provincial Clinical College of Fujian

Medical University, Fujian Provincial Hospital, Fuzhou, China
}

(C) The Author(s). 2021 Open Access This article is licensed under a Creative Commons Attribution 4.0 International License, which permits use, sharing, adaptation, distribution and reproduction in any medium or format, as long as you give appropriate credit to the original author(s) and the source, provide a link to the Creative Commons licence, and indicate if changes were made. The images or other third party material in this article are included in the article's Creative Commons licence, unless indicated otherwise in a credit line to the material. If material is not included in the article's Creative Commons licence and your intended use is not permitted by statutory regulation or exceeds the permitted use, you will need to obtain permission directly from the copyright holder. To view a copy of this licence, visit http://creativecommons.org/licenses/by/4.0/ The Creative Commons Public Domain Dedication waiver (http://creativecommons.org/publicdomain/zero/1.0/) applies to the data made available in this article, unless otherwise stated in a credit line to the data. 


\section{Background}

Sepsis and septic shock remain the main causes of admission to the intensive care unit (ICU) and death in critically ill patients [1]. Serum lactate is considered an index of tissue hypoxia and/or a hypermetabolic state with enhanced glycolysis, which are commonly seen in sepsis and septic shock [2]. Besides, it has been shown by a large number of studies that an elevated lactate level is associated with increased mortality [3]. Therefore, a lactate-guided therapy with repeated lactate measurements has been recommended by the Surviving Sepsis Campaign (SSC) guidelines [4].

An elevated blood lactate concentration at any time point is a "static" index to reflect the balance in its production and clearance at that very moment. In contrast, a "dynamic" index can reflect the change of lactate homeostasis. In other words, it describes not only the magnitude but also the duration and trend over time. Some "dynamic" indices have been proposed to better predict outcomes. In the early 1980s, Vincent et al. introduced the concept of serial lactate measurement in circulatory shock patients. They found that survivors had at least a 10\% decrease in lactate during the first 60 min of treatment [5]. The time variables in lactate kinetics were continued to be studied and further advocated for lactate-guided treatment protocols in the following years [6-12].

A new approach to examine the dynamic lactate changes has been proposed in the 2010s, which incorporates both the magnitude of change and the time interval of such change [13-16]. The dynamic change of lactate over time is plotted, and the area under the curve (AUC) represents the overall lactate burden, termed "lactate area" [14], "lactate area score" $[15,16]$ or "lactate load" [17]. With the AUC divided by the time interval, the result represents the averaged lactate load in this period, termed "time-weighted average lactate" [13] or "normalized lactate load" [17]. Such indices have been shown to be associated with worse outcomes in pediatric septic shock patients [14], post-cardiosurgical patients [17] and heterogeneous cohorts of critically ill patients [13]. In addition, adult septic shock patients were also investigated in two studies $[15,16]$. However, these variables have not been validated in a large cohort of adult septic shock patients. In the present study, we aimed to evaluate the association between normalized lactate load and 28-day mortality in adult septic shock patients by analyzing data from a large critical care database.

\section{Methods}

\section{Data source}

Data were collected from the Medical Information Mart for Intensive Care-III (MIMIC-III) [18]. In brief, MIMI C-III database is maintained by the Laboratory for
Computational Physiology at the Massachusetts Institute of Technology. It contains de-identified health-related data associated with over forty thousand patients who stayed in critical care units of the Beth Israel Deaconess Medical Center between 2001 and 2012. The establishment of the database was approved by the institutional review boards of the Massachusetts Institute of Technology (Cambridge, MA) and Beth Israel Deaconess Medical Center (Boston, MA). Consent was obtained for the original data collection and therefore waived for the present study by the Institutional Review Board of Fujian Provincial Hospital. Data were extracted by Dr. Han Chen and Dr. Shu-Rong Gong, who completed the online training course of the National Institutes of Health (certification number: HC 36014736, SRG 35606844). The study was designed and conducted in accordance with relevant guidelines and regulations (Declaration of Helsinki).

\section{Data extraction}

PostgreSQL tools Ver. 10 was used for data extraction. The following data were extracted by using Structured Query Language (SQL): age, gender, co-morbidities, length of ICU stay, sequential organ failure assessment (SOFA) score, vital signs, first-day lab results (such as white blood cell count, the levels of hemoglobin, platelet, bilirubin, blood urea nitrogen, creatinine and albumin), 28-day mortality, and the presence of septic shock. Besides, all arterial lactate values and the chart time of measurement were collected for further calculation. We used the term "lactate load" to represent the AUC of lactate, which accounts for the cumulative effect of hyperlactatemia over time. Meanwhile, we used the term "normalized lactate load" to represent the quotient of AUC divided by time, which accounts for the average intensity of hyperlactatemia. The calculation is detailed in Fig. 1.

Septic shock patients were screened for inclusion. The inclusion criteria were: 1) Patients fulfilled the definition of septic shock according to the sepsis-3.0 criteria [1]. 2) Patients have at least one lactate measurement within the first $24 \mathrm{~h}$ of ICU stay. The exclusion criteria were: 1 ) Length of ICU stay < $24 \mathrm{~h}$. 2) Age less than 18 years. For patients who have multiple ICU admissions, only the first ICU stay was selected.

\section{Statistical analysis}

Kolmogorov-Smirnov test was used for the assessment of the normality of distribution. Continuous variables were presented as mean with standard deviation (for normal distribution) or median with interquartile range (for non-normal distribution). Student's $t$-test or Wilcoxon rank-sum test were used as appropriate. Categorical variables were presented as counts (percentages) and 


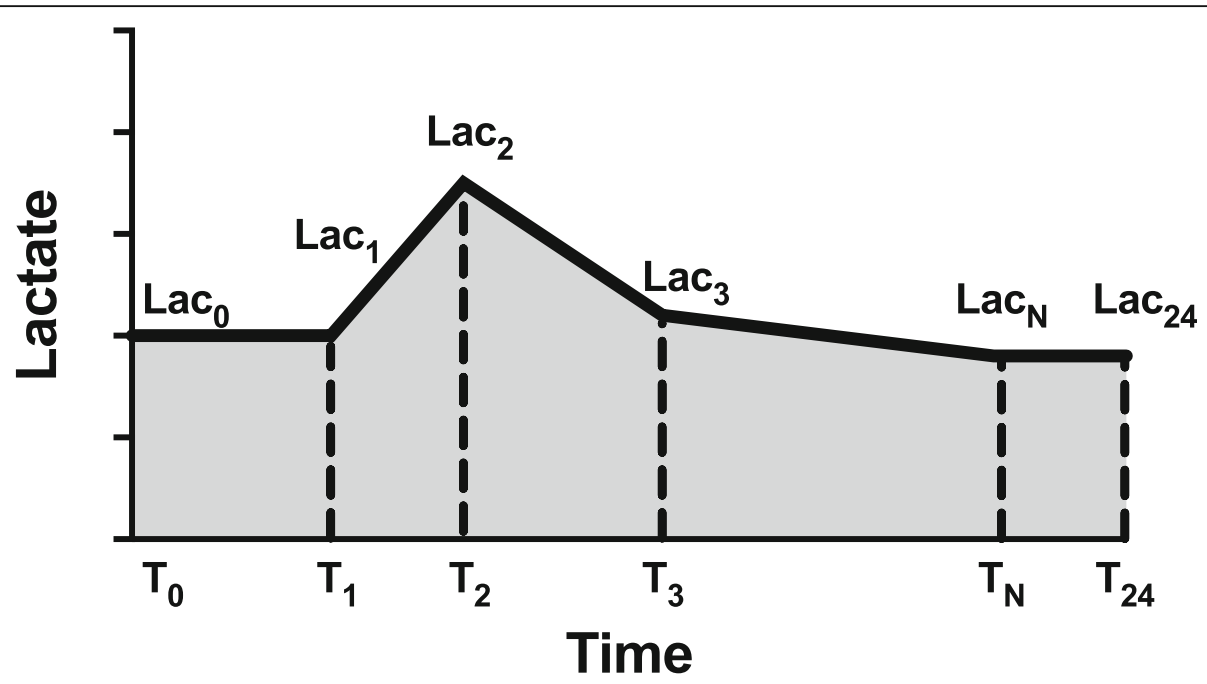

Fig. 1 Diagram describing the calculation of lactate load and normalized lactate load. Each "T" on the x-axis represents the chart time of lactate measurement, while the corresponding "Lac" represents the corresponding lactate values. Lactate load was calculated as: $\left.\left(\left(\operatorname{Lac}_{1}+\operatorname{Lac}_{0}\right) / 2\right)\right) *\left(T_{1}-\right.$ $\left.\left.\left.T_{0}\right)+\left(\left(\operatorname{Lac}_{2}+\operatorname{Lac}_{1}\right) / 2\right)\right) *\left(T_{2}-T_{1}\right)+\ldots+\left(\left(\operatorname{Lac}_{24}+\operatorname{Lac}_{N}\right) / 2\right)\right) *\left(T_{24}-T_{N}\right)$. Where the $T_{0}$ represents ICU admission time, and the corresponding Lac was defined as equals to $\mathrm{Lac}_{1}$. Similarly, $\mathrm{Lac}_{24}$ (lactate value at $24 \mathrm{~h}$ after admission) was defined as equals to $\mathrm{LaC}_{\mathrm{N}}$, where the $\mathrm{LaC}_{\mathrm{N}}$ represents the last measured lactate value in the $24 \mathrm{~h}$. Normalized lactate load was calculated as lactate load divided by $\left(\mathrm{T}_{24}-\mathrm{T}_{0}\right)$, which actually equals to $24 \mathrm{~h}$

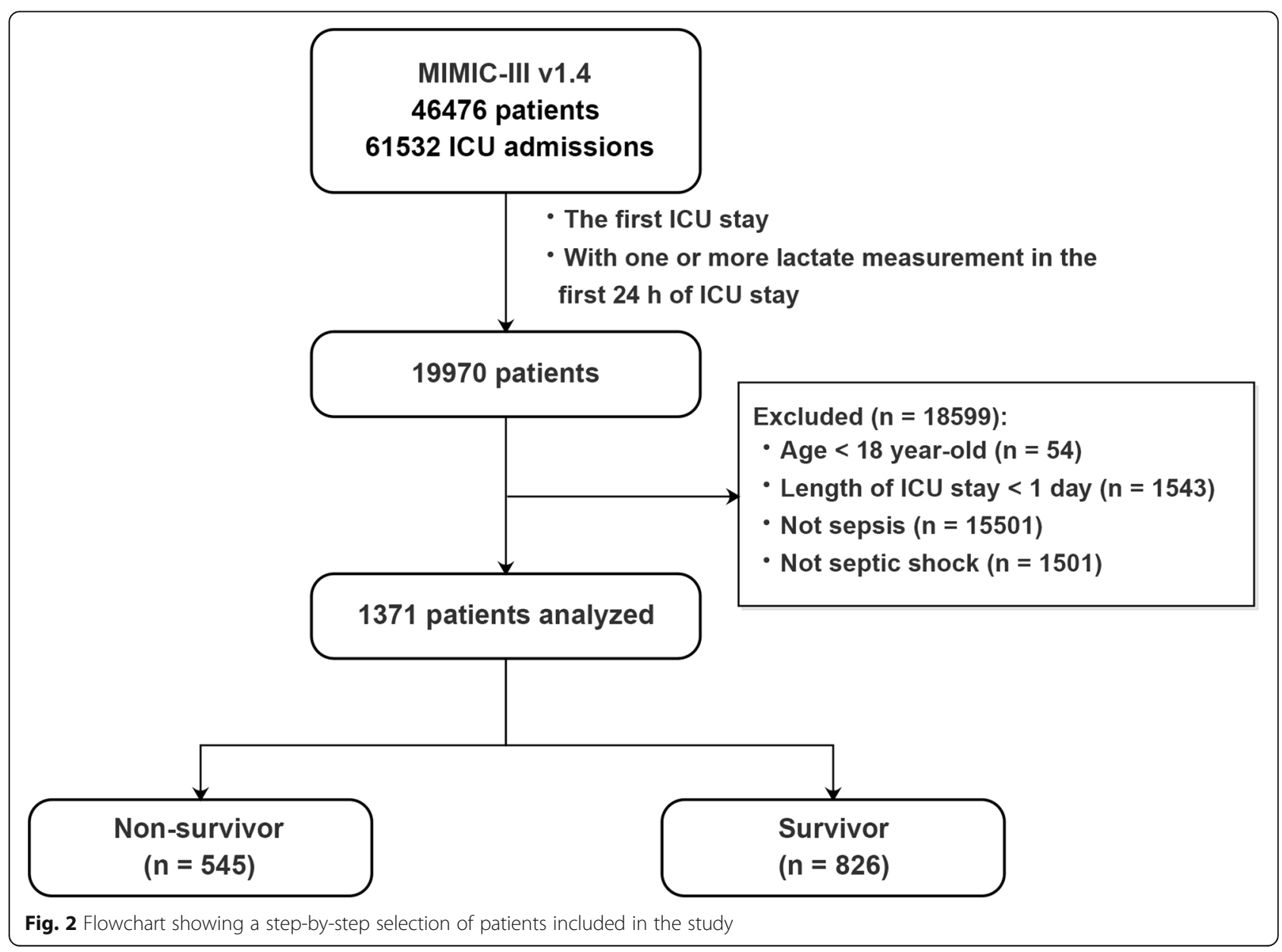


compared using the chi-square test. The correlation among maximum lactate, initial lactate and normalized lactate load was tested by the Pearson correlation analysis.

Univariate and multivariate logistic regression analyses with stepwise elimination were performed to evaluate the relationship between mortality and lactate variables. Variables with a $p$-value $<0.2$ were included in the multivariate analysis. We artificially excluded creatinine and bilirubin because they are already included in the SOFA score. Receiver-operating characteristic (ROC) curves were constructed to determine the performance of initial lactate, maximum lactate, normalized lactate load and the SOFA score in predicting 28-day mortality. The Delong test was used to compare the AUCs of the ROC curves [19]. A subgroup analysis was performed in patients with a maximum lactate of $\geq 4 \mathrm{mmol} / \mathrm{L}$ since that lactate $>4 \mathrm{mmol} / \mathrm{L}$ has long been used as an indicator of tissue hypoperfusion [20]. STATA (ver. 15.1, StataCorp., TX, USA) and MedCalc (ver. 15.8, MedCalc Software, Ostend, Belgium) were used for data analysis. All reported $p$-values are two-sided, and a $p<0.05$ was considered significant.

\section{Results}

A total of 1371 septic shock patients were included, and the 28 -day mortality was $39.8 \%$ (826 survivors, 545 nonsurvivors, Fig. 2). Baseline patient characteristics are summarized in Table 1 . In brief, non-survivors were older $(66.5 \pm 16.3$ vs. $69.2 \pm 14.7$ years old, $p=0.001)$, and had higher SOFA score $(8[5,10]$ vs. $10[8,13]$, $p<0.001)$. Maximum anion gap, maximum potassium, maximum bilirubin, maximum creatinine, maximum blood urea nitrogen, maximum activated partial thromboplastin time and maximum international normalized ratio were significantly higher in the nonsurvivors; whereas the maximum sodium, maximum chloride, minimum hematocrit, minimum albumin, minimum hemoglobin, minimum platelet were significantly lower in the non-survivors. In addition, nonsurvivors were more likely to have liver disease and malignant tumors.

Non-survivors had significantly higher initial lactate $(3.9 \pm 2.9$ vs. $2.8 \pm 1.7 \mathrm{mmol} / \mathrm{L}, p<0.001)$, maximum lactate $(5.8 \pm 3.8$ vs. $4.3 \pm 2.2 \mathrm{mmol} / \mathrm{L}, p<0.001)$, lactate load (94.3 \pm 71.8 vs. $61.1 \pm 36.4 \mathrm{mmol} \cdot \mathrm{hr} . / \mathrm{L}, p<0.001)$, and normalized lactate load $(3.9 \pm 3.0$ vs. $2.5 \pm 1.5 \mathrm{mmol} /$ $\mathrm{L}, p<0.001)$. There was a significant correlation between normalized lactate load and maximum lactate $(r=0.850, p<0.001)$, and between normalized lactate load and initial lactate $(r=0.794, p<0.001)$.

We generated ROC curves for three lactate indicators (Fig. 3). Normalized lactate load had the strongest predictive power in both the overall population and the patients with greater maximum lactate $(\geq 4 \mathrm{mmol} / \mathrm{L}$, Table 2). The AUCs of initial lactate, maximum lactate and normalized lactate load were 0.623 (95\% confidence interval [CI]: $0.596-0.648$, with a cut-off value of 4.4 $\mathrm{mmol} / \mathrm{L}), 0.606(0.580-0.632$, with a cut-off value of 2.6 $\mathrm{mmol} / \mathrm{L})$ and $0.681(0.656-0.706$, with a cut-off value of $2.6 \mathrm{mmol} / \mathrm{L}$ ), respectively. The AUC of normalized lactate load was significantly greater than both initial lactate and maximum lactate (all $p<0.001$ ). There was no difference between initial lactate and maximum lactate $(p=0.207)$. In the subgroup of patients with a maximum lactate of $\geq 4 \mathrm{mmol} / \mathrm{L}$, the AUCs of initial lactate, maximum lactate and normalized lactate load were 0.609 (0.571-0.645, with a cut-off value of $5.1 \mathrm{mmol} / \mathrm{L}), 0.642$ (0.604-0.678, with a cut-off value of $6.9 \mathrm{mmol} / \mathrm{L})$ and $0.696(0.660-0.730$, with a cut-off value of $3.6 \mathrm{mmol} / \mathrm{L})$. The AUC of normalized lactate load was significantly greater than both initial lactate and maximum lactate $(p<0.001$ and $p=0.005$, respectively). There was no difference between initial lactate and maximum lactate $(p=0.124)$. SOFA score had a similar predictive value to normalized lactate load in both the overall population (AUC 0.683 [0.658-0.708], $p=0.891$ ) and patients with a maximum lactate of $\geq 4 \mathrm{mmol} / \mathrm{L}$ (AUC 0.706 [0.6710.740], $p=0.617$ ).

In the multivariate logistic regression model, normalized lactate load, age, SOFA score, maximum anion gap, maximum chloride, maximum potassium, minimum hemoglobin, and the presence of malignant tumor were identified as independent risk factors of 28-day mortality (Table 3). For every $1 \mathrm{mmol} / \mathrm{L}$ increase in normalized lactate load the risk of 28-day mortality increased by $30 \%$ (odds ratio $[\mathrm{OR}]=1.30,95 \% \mathrm{CI} 1.20$ to 1.42 , $p<0.001)$.

\section{Discussion}

In this study, we found that normalized lactate load was independently associated with 28-day mortality in a large cohort of septic shock patients. Normalized lactate load had better accuracy than both initial and maximum lactate in determining the prognosis of septic shock patients.

There is a large number of studies indicating that blood lactate concentration closely relates to survival of patients with septic shock [2, 21, 22]. However, a single isolated lactate level is not good enough for predicting the outcome or guiding therapy and the change of lactate could provide more information $[5,9,23]$. For this reason, the concept of dynamic change of lactate is attractive. Serial lactate and lactate clearance have been proposed to guide shock resuscitation [5, 9]. Lactate clearance can effectively reflect dynamic changes in lactate levels but cannot provide information regarding the severity of hyperlactatemia. The magnitude of organ 
Table 1 Comparisons of the clinical characteristics between survivors and non-survivors in the first $24 \mathrm{~h}$

\begin{tabular}{|c|c|c|c|}
\hline & $\begin{array}{l}\text { Survivors } \\
(n=826)\end{array}$ & $\begin{array}{l}\text { Non-survivors } \\
(n=545)\end{array}$ & $p$ value \\
\hline Male & $386(46.7)$ & $238(43.7)$ & 0.265 \\
\hline Age (years) & $66.5 \pm 16.3$ & $69.2 \pm 14.7$ & 0.001 \\
\hline SOFA score & $8(5,10)$ & $10(8,13)$ & $<0.001$ \\
\hline \multicolumn{4}{|l|}{ Comorbidities } \\
\hline Obesity & $51(6.2)$ & $28(5.1)$ & 0.420 \\
\hline Congestive heart failure & $277(33.5)$ & $192(35.2)$ & 0.518 \\
\hline Cardiac arrhythmias & $262(31.7)$ & $199(36.5)$ & 0.066 \\
\hline Valvular disease & $91(11)$ & $61(11.2)$ & 0.919 \\
\hline Hypertension & 139 (16.8) & $101(18.5)$ & 0.416 \\
\hline Chronic pulmonary disease & $162(19.6)$ & $109(20)$ & 0.860 \\
\hline Diabetes mellitus & $282(34.1)$ & $182(33.4)$ & 0.775 \\
\hline Hypothyroidism & $103(12.5)$ & $68(12.5)$ & 0.997 \\
\hline Liver disease & $92(11.1)$ & $102(18.7)$ & $<0.001$ \\
\hline AIDS & $4(0.5)$ & $0(0)$ & 0.104 \\
\hline Tumor & $76(9.2)$ & $108(19.8)$ & $<0.001$ \\
\hline \multicolumn{4}{|l|}{ Laboratory results in the first $24 \mathrm{~h}$} \\
\hline Maximum anion gap (mmol/L) & $18.9 \pm 4.9$ & $20.9 \pm 6$ & $<0.001$ \\
\hline Maximum sodium (mmol/L) & $141.3 \pm 6.4$ & $140.6 \pm 6.4$ & 0.036 \\
\hline Maximum potassium (mmol/L) & $4.8 \pm 0.9$ & $5.1 \pm 1.1$ & $<0.001$ \\
\hline Maximum chloride (mmol/L) & $110.6 \pm 7.4$ & $108.9 \pm 8.1$ & $<0.001$ \\
\hline Maximum bilirubin (mg/L) & $2.1 \pm 4.2$ & $3.9 \pm 6.4$ & $<0.001$ \\
\hline Maximum creatinine (mg/dL) & $2.2 \pm 1.9$ & $2.5 \pm 1.7$ & 0.002 \\
\hline Maximum blood urea nitrogen (mg/dL) & $39.4 \pm 25.4$ & $49.6 \pm 30$ & $<0.001$ \\
\hline Maximum blood glucose (mg/dL) & $206.6 \pm 119.9$ & $207.8 \pm 112.3$ & 0.853 \\
\hline Minimum albumin (g/dL) & $2.8 \pm 0.7$ & $2.5 \pm 0.7$ & $<0.001$ \\
\hline Minimum hematocrit (\%) & $29 \pm 5.4$ & $28.2 \pm 5.9$ & 0.008 \\
\hline Minimum hemoglobin (g/dL) & $9.7 \pm 1.8$ & $9.3 \pm 2$ & $<0.001$ \\
\hline Minimum platelet (K/uL) & $186.3 \pm 122.6$ & $159 \pm 121.7$ & $<0.001$ \\
\hline Maximum white blood cell count (K/LL) & $19.8 \pm 13.3$ & $19.6 \pm 23$ & 0.835 \\
\hline Maximum APTT (sec) & $47.1 \pm 28.3$ & $57.3 \pm 34.8$ & $<0.001$ \\
\hline Maximum INR (sec) & $2 \pm 1.5$ & $2.5 \pm 2.1$ & $<0.001$ \\
\hline \multicolumn{4}{|l|}{ Lactate related variables } \\
\hline Initial lactate (mmol/L) & $2.8 \pm 1.7$ & $3.9 \pm 2.9$ & $<0.001$ \\
\hline Maximum lactate $(\mathrm{mmol} / \mathrm{L})$ & $4.3 \pm 2.2$ & $5.8 \pm 3.8$ & $<0.001$ \\
\hline Lactate load (mmol.hr./L) & $61.1 \pm 36.4$ & $94.3 \pm 71.8$ & $<0.001$ \\
\hline Normalized lactate load (mmol/L) & $2.5 \pm 1.5$ & $3.9 \pm 3.0$ & $<0.001$ \\
\hline
\end{tabular}

Data are presented as mean \pm standard deviation or median (interquartile range) for continuous variables, and counts (percentages) for categorical variables AIDS acquired immunodeficiency syndrome, APTT activated partial thromboplastin time, INR international normalized ratio, SOFA sequential organ failure assessment

dysfunction of septic shock depends upon the magnitude and duration of hypoxia. In this regard, the production of the actual lactate concentrations and the duration of hyperlactatemia can serve as a marker of organ hypoxia, which is the cause of organ dysfunction and death [2].
As previously mentioned, this index of lactate variation has various names. In this study, we adopted the terms "lactate load" and "normalized lactate load," which were first proposed by Zhang et al. [17], to define lactate variation over time. By using the term "lactate load," one can express the concept of hypoxic load or hypoxic 

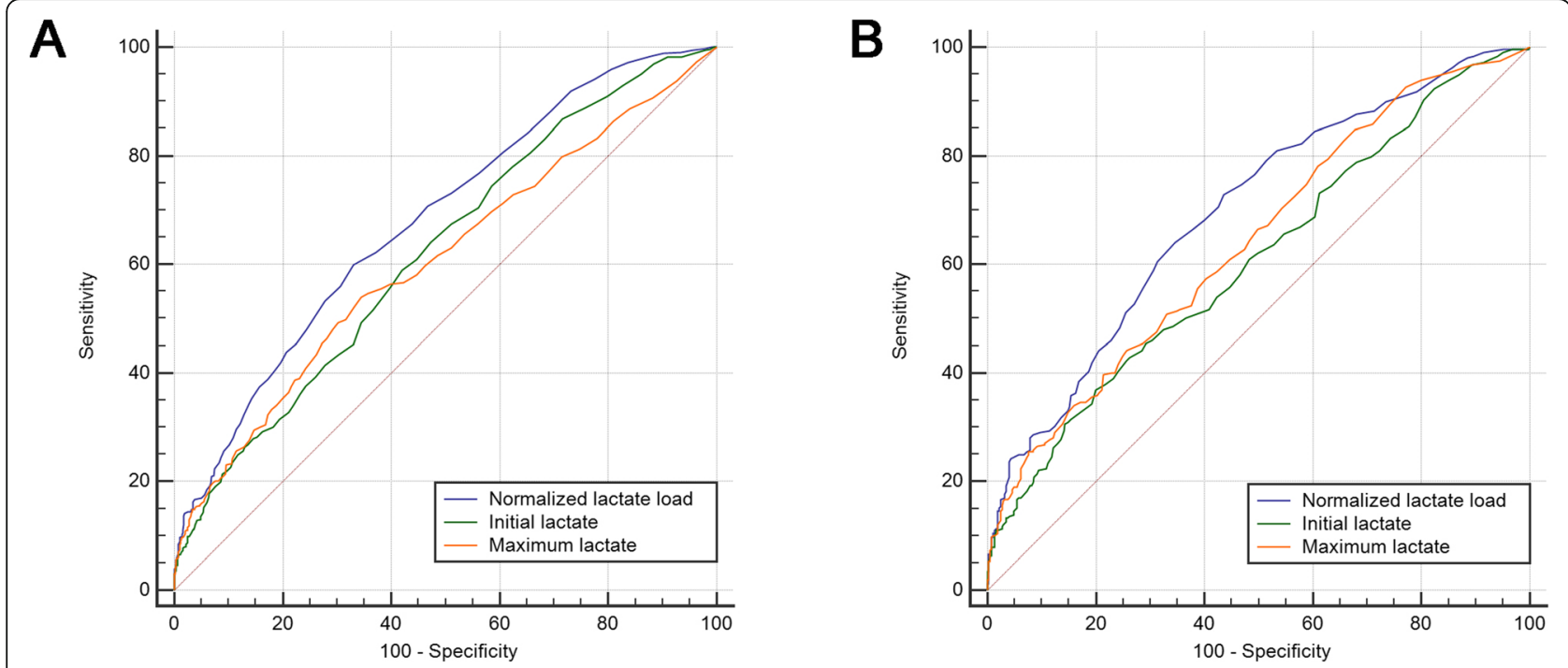

Fig. 3 Comparisons among receiver-operating characteristic curves. Panel a: Comparison of receiver-operating characteristic (ROC) curves between initial lactate, maximum lactate and normalized lactate load in all included patients. The AUC of normalized lactate load was significantly greater than the initial lactate and maximum lactate (all $p<0.001)$. There was no difference between initial lactate and maximum lactate $(p=$ 0.207). Panel $\mathbf{b}$ : Comparison of ROC in patients with a maximum lactate $\geq 4 \mathrm{mmol} / \mathrm{L}$. The AUC of normalized lactate load was significantly greater than both initial lactate and maximum lactate $(p<0.001$ and $p=0.005$, respectively). There was no difference between initial lactate and maximum lactate $(p=0.124)$

burden in septic shock patients. Similarly, the term "normalized lactate load" reflects the "standardized" or the "averaged" hypoxic burden in the early phase of septic shock. Another advantage of using normalized lactate load is that it is easier to understand and apply in daily practice. Unlike the lactate area with a unit of "mmol.hr./L," whose physiological meaning is difficult to understand, normalized lactate load is expressed in "mmol/L" (same as lactate concentration), and this makes it easy to interpret and allows one to compare it with a newly obtained lactate value directly.

Our data suggest that normalized lactate load may be an independent risk factor of mortality in septic shock patients. Although similar findings have been found in a

Table 2 Performance of normalized lactate load, initial lactate and maximum lactate in predicting mortality

\begin{tabular}{|c|c|c|c|c|c|c|c|c|}
\hline & $\begin{array}{l}\text { Cut- } \\
\text { off } \\
\text { value }\end{array}$ & $\begin{array}{l}\text { Area under } \\
\text { curve }(95 \% \\
\text { Cl) } \\
\end{array}$ & $\begin{array}{l}\text { Sensitivity } \\
(\%, 95 \mathrm{Cl})\end{array}$ & $\begin{array}{l}\text { Specificity } \\
(\%, 95 \mathrm{Cl})\end{array}$ & $\begin{array}{l}\text { Positive } \\
\text { likelihood ratio } \\
(95 \% \mathrm{Cl})\end{array}$ & $\begin{array}{l}\text { Negative } \\
\text { likelihood ratio } \\
(95 \% \mathrm{Cl})\end{array}$ & $\begin{array}{l}\text { Positive } \\
\text { predictive value } \\
(95 \% \mathrm{Cl})\end{array}$ & $\begin{array}{l}\text { Negative } \\
\text { predictive value } \\
(95 \% \mathrm{Cl})\end{array}$ \\
\hline \multicolumn{9}{|c|}{ In overall population $(n=1371)$} \\
\hline $\begin{array}{l}\text { Normalized } \\
\text { lactate load } \\
(\mathrm{mmol} / \mathrm{L})\end{array}$ & 2.6 & $\begin{array}{l}0.681(0.656- \\
0.706)\end{array}$ & $\begin{array}{l}60(55.8- \\
64.1)\end{array}$ & $\begin{array}{l}66.95 \\
(63.6-70.2)\end{array}$ & $1.82(1.6-2.0)$ & $0.6(0.5-0.7)$ & $54.5(50.4-58.5)$ & $71.7(68.4-74.9)$ \\
\hline $\begin{array}{l}\text { Initial lactate } \\
(\mathrm{mmol} / \mathrm{L})\end{array}$ & 2.6 & $\begin{array}{l}0.623(0.596- \\
0.648)\end{array}$ & $\begin{array}{l}58.9(54.6- \\
63.1)\end{array}$ & $\begin{array}{l}57.99 \\
(54.5-61.4)\end{array}$ & $1.4(1.3-1.6)$ & $0.71(0.6-0.8)$ & $48.1(44.2-51.9)$ & $68.1(64.6-71.6)$ \\
\hline $\begin{array}{l}\text { Maximum } \\
\text { Lactate (mmol/ } \\
\text { L) }\end{array}$ & 4.4 & $\begin{array}{l}0.606(0.580- \\
0.632)\end{array}$ & $\begin{array}{l}53.94 \\
(49.7-58.2)\end{array}$ & $\begin{array}{l}65.5(62.1- \\
68.7)\end{array}$ & $1.56(1.4-1.8)$ & $0.7(0.6-0.8)$ & $50.8(46.6-54.9)$ & $68.3(64.9-71.5)$ \\
\hline \multicolumn{9}{|c|}{ In patients with a maximum lactate $\geq 4 \mathrm{mmol} / \mathrm{L}(n=686)$} \\
\hline $\begin{array}{l}\text { Normalized } \\
\text { lactate load } \\
\text { (mmol/L) }\end{array}$ & 3.6 & $\begin{array}{l}0.696(0.660- \\
0.730)\end{array}$ & $\begin{array}{l}64.04 \\
(58.5-69.3)\end{array}$ & $\begin{array}{l}65.31 \\
(60.2-70.2)\end{array}$ & $1.85(1.6-2.2)$ & $0.55(0.5-0.6)$ & $61.3(55.8-66.6)$ & $67.9(62.8-72.7)$ \\
\hline $\begin{array}{l}\text { Initial lactate } \\
(\mathrm{mmol} / \mathrm{L})\end{array}$ & 5.1 & $\begin{array}{l}0.609(0.571- \\
0.645)\end{array}$ & $\begin{array}{l}36.91 \\
(31.6-42.5)\end{array}$ & $\begin{array}{l}79.95 \\
(75.5-83.9)\end{array}$ & $1.84(1.4-2.4)$ & $0.79(0.7-0.9)$ & $61.3(54.0-68.2)$ & $59.6(55.1-64.0)$ \\
\hline $\begin{array}{l}\text { Maximum } \\
\text { Lactate (mmol/ } \\
\text { L) }\end{array}$ & 6.9 & $\begin{array}{l}0.642(0.604- \\
0.678)\end{array}$ & $\begin{array}{l}44.16 \\
(38.6-49.8)\end{array}$ & $\begin{array}{l}74.25 \\
(69.5-78.6)\end{array}$ & $1.72(1.4-2.1)$ & $0.75(0.7-0.8)$ & $59.6(53.0-65.9)$ & $60.8(56.1-65.3)$ \\
\hline
\end{tabular}


Table 3 Multivariate logistic regression models for the prediction of 28-day mortality

\begin{tabular}{llll}
\hline Effect & Odds ratio & $\mathbf{9 5 \% ~ C l}$ & $\boldsymbol{p}$ value \\
\hline Normalized lactate load & 1.30 & $(1.2,1.42)$ & $<0.001$ \\
Age & 1.03 & $(1.02,1.03)$ & $<0.001$ \\
SOFA score & 1.16 & $(1.12,1.2)$ & $<0.001$ \\
Maximum anion gap & 0.97 & $(0.94,0.99)$ & 0.036 \\
Maximum chloride & 0.97 & $(0.95,0.98)$ & $<0.001$ \\
Maximum potassium & 1.31 & $(1.15,1.48)$ & $<0.001$ \\
Tumor & 2.32 & $(1.63,3.3)$ & $<0.001$ \\
Minimum hemoglobin & 0.92 & $(0.86,0.98)$ & 0.030 \\
Constant & 0.44 & $(0.05,3.62)$ & 0.444 \\
\hline
\end{tabular}

SOFA sequential organ failure assessment, $\mathrm{Cl}$ confidence interval

few previous studies [13-16], it has not been investigated in a large cohort of adult septic shock patients like our study population. Nichol et al. found that timeweighted average lactate, which was defined as "summing the mean value between consecutive time points multiplied by the period of time between consecutive time points and then dividing by the total time", was independently predictive of hospital mortality in a heterogeneous cohort of critically ill patients, with an OR of 1.37 (95\% CI: 1.29 to 1.45 ) [13]. In the present study, we chose 28-day mortality as outcome, and our finding is close to theirs $(\mathrm{OR}=1.30)$. Similarly, $\mathrm{Yu}$ et al. reported that early lactate area score, which was defined as "the sum of the AUC measured at 2, 4, 6, and 12 hours following the initial measurement", was 0.659 in predicting 28-day mortality, which is also close to our findings. On the other hand, Kim et al. reported a higher AUC (AUC $=0.828$ ) of the lactate area (defined as the sum of the AUC of serial lactate levels measured during the 24 $\mathrm{h}$ following admission) for 28-day mortality. In their study, 65 pediatric patients with septic shock were included, and the overall 28-day mortality was $26.2 \%$ [14]. In addition, Wang et al. also reported a higher AUC of lactate area score (defined as the sum of the AUC of serial lactate levels measured during the $24 \mathrm{~h}$ following admission divided by 24) in predicting 28-day mortality (AUC $=0.758$ ). In their study, 115 elderly (age $\geq 65$ years) patients with septic shock were included, and the overall 28 -day mortality rate was $67.0 \%$. Apart from the difference in study populations and sample sizes, one more important difference between our study and previous studies is that we reported not only lactate load (like the previous studies, although the terms may differ) but also normalized lactate load, which was not always included in previous studies.

Several limitations in the present study should be considered. First, our study was a retrospective study based on electronic healthcare records, and therefore limited by the nature of the retrospective design and the source of data used. Second, there was not a standard protocol of lactate measurement in this study, and it is possible that lactate load and normalized lactate load were underestimated or overestimated. The lack of a standard lactate measurement protocol also precluded the calculation of lactate clearance, which is another traditionally employed index of lactate variation $[6,11]$. However, our results simply reflect the actual effect of normalized lactate load measurement in real-world clinical practice. Third, for patients with a single lactate measurement, normalized lactate load was equal to their single lactate measurement and this may also underestimate or overestimate lactate load and normalized lactate load. Among the 241 (17.6\%) patients who had only a single lactate measurement, 215 (89.2\% of the 241 patients and $15.7 \%$ of the whole study population) had a lactate value of $\leq 4 \mathrm{mmol} / \mathrm{L}$. Clinicians may have considered a lactate $\leq 4 \mathrm{mmol} / \mathrm{L}$ to be acceptable in the absence of other evidence of tissue hypoxia. Notably, lactate $>4 \mathrm{mmol} / \mathrm{L} \mathrm{sig-}$ nificantly increases ICU admission rates and mortality rates $[9,24]$. Fourth, normalized lactate area cannot distinguish a decreasing or increasing pattern of lactate kinetic change. Finally, The AUC, sensitivity and specificity, along with the negative and positive predictive value of normalized lactate load were not very high. Interestingly, we found similar AUCs between normalized lactate load and SOFA score (both are not satisfactory enough). A single indicator cannot accurately predict the prognosis in a highly heterogeneous population like septic shock patients and should be integrated with a variety of clinical manifestations, laboratory exams and imaging.

\section{Conclusions}

Normalized lactate load is independently associated with 28-day mortality in adult septic shock patients. Normalized lactate load had better accuracy than both initial and maximum lactate in determining the prognosis of septic shock patients.

\section{Abbreviations}

AUC: Area under curve; Cl: Confidence interval; ICU: Intensive care unit; MIMI C: Medical Information Mart for Intensive Care; OR: Odds ratio; ROC: Receiveroperating characteristic; SOFA: Sequential organ failure assessment;

SQL: Structured Query Language; SSC: Surviving Sepsis Campaign

\section{Acknowledgments \\ None.}

\section{Authors' contributions}

Conception and design: HC, RGY; Data collection and analysis: HC, SRG; Drafting the manuscript: HC. All authors have read, edited, and approved the manuscript.

\section{Funding}

$\mathrm{HC}$ is supported by the National Natural Science Foundation of China (Grant No. 81701942) and the High-level Hospital Foster Grants from Fujian Provincial Hospital (Grant Number: 2020HSJJ02). Rong-Guo Yu is supported by the 
High-level hospital grants from Fujian Provincial Hospital (Grant number: (2017)510\#).

\section{Availability of data and materials}

The data that support the findings of this study are available from the MIMI C-III database, but restrictions apply to the availability of these data, which were used under license for the current study, and so are not publicly available. Data are however available from the authors upon reasonable request and with permission of the holder of the database.

\section{Ethics approval and consent to participate}

The institutional review boards of the Massachusetts Institute of Technology (Cambridge, MA) and Beth Israel Deaconess Medical Center (Boston, MA) approved the establishment of the database. Consent was obtained for the original data collection, informed consent was obtained from all subjects or, if subjects are under 18, from a parent and/or legal guardian. Therefore, informed consent was waived for the present study by the Institutional Review Board of Fujian Provincial Hospital. The study was designed and conducted in accordance with relevant guidelines and regulations (Declaration of Helsinki), and the study protocol was approved by Institutional Review Board of Fujian Provincial Hospital.

\section{Consent for publication}

Not applicable.

\section{Competing interests}

The authors declare that they have no competing interests.

Received: 22 September 2020 Accepted: 30 December 2020 Published online: 12 January 2021

\section{References}

1. Singer M, Deutschman CS, Seymour CW, Shankar-Hari M, Annane D, Bauer $M$, et al. The third international consensus definitions for sepsis and septic shock (Sepsis-3). JAMA. 2016;315:801-10.

2. Kraut JA, Madias NE. Lactic acidosis. N Engl J Med. 2014;371:2309-19.

3. Khodashahi R, Sarjamee S. Early lactate area scores and serial blood lactate levels as prognostic markers for patients with septic shock: a systematic review. Infect Dis. 2020;52:451-63.

4. Rhodes A, Evans LE, Alhazzani W, Levy MM, Antonelli M, Ferrer R, et al. Surviving sepsis campaign: international guidelines for management of sepsis and septic shock: 2016. Intensive Care Med. 2017:43:304-77.

5. Vincent JL, Dufaye P, Berré J, Leeman M, Degaute JP, Kahn RJ. Serial lactate determinations during circulatory shock. Crit Care Med. 1983:11:449-51.

6. Abramson D, Scalea TM, Hitchcock R, Trooskin SZ, Henry SM, Greenspan J. Lactate clearance and survival following injury. J Trauma. 1993;35:584-8 discussion 8-9.

7. Bakker J, Gris P, Coffernils M, Kahn RJ, Vincent JL. Serial blood lactate levels can predict the development of multiple organ failure following septic shock. Am J Surg. 1996:171:221-6.

8. Suistomaa M, Ruokonen E, Kari A, Takala J. Time-pattern of lactate and lactate to pyruvate ratio in the first 24 hours of intensive care emergency admissions. Shock. 2000;14:8-12.

9. Nguyen HB, Rivers EP, Knoblich BP, Jacobsen G, Muzzin A, Ressler JA, et al. Early lactate clearance is associated with improved outcome in severe sepsis and septic shock. Crit Care Med. 2004;32:1637-42.

10. Arnold RC, Shapiro NI, Jones AE, Schorr C, Pope J, Casner E, et al. Multicenter study of early lactate clearance as a determinant of survival in patients with presumed sepsis. Shock. 2009:32:35-9.

11. Jones AE, Shapiro NI, Trzeciak S, Arnold RC, Claremont HA, Kline JA. Lactate clearance vs central venous oxygen saturation as goals of early sepsis therapy: a randomized clinical trial. JAMA. 2010;303:739-46.

12. Jansen TC, van Bommel J, Schoonderbeek FJ, Sleeswijk Visser SJ, van der Klooster JM, Lima AP, et al. Early lactate-guided therapy in intensive care unit patients: a multicenter, open-label, randomized controlled trial. Am J Respir Crit Care Med. 2010;182:752-61.

13. Nichol A, Bailey M, Egi M, Pettila V, French C, Stachowski E, et al. Dynamic lactate indices as predictors of outcome in critically ill patients. Crit Care. 2011;15:R242.

14. Kim YA, Ha EJ, Jhang WK, Park SJ. Early blood lactate area as a prognostic marker in pediatric septic shock. Intensive Care Med. 2013;39:1818-23.
15. Wang $H, L i Z$, Yin $M$, Chen XM, Ding SF, Li C, et al. Combination of acute physiology and chronic health evaluation II score, early lactate area, and Nterminal prohormone of brain natriuretic peptide levels as a predictor of mortality in geriatric patients with septic shock. J Crit Care. 2015;30:304-9.

16. Yu G, Yoo SJ, Lee SH, Kim JS, Jung S, Kim YJ, et al. Utility of the early lactate area score as a prognostic marker for septic shock patients in the emergency department. Acute Crit Care. 2019;34:126-32.

17. Zhang $\mathrm{Z}, \mathrm{Ni} \mathrm{H}$. Normalized lactate load is associated with development of acute kidney injury in patients who underwent cardiopulmonary bypass surgery. PLoS One. 2015;10:e0120466.

18. Johnson AE, Pollard TJ, Shen L, Lehman LW, Feng M, Ghassemi M, et al. MIMIC-III, a freely accessible critical care database. Sci Data. 2016;3:160035.

19. DeLong ER, DeLong DM, Clarke-Pearson DL. Comparing the areas under two or more correlated receiver operating characteristic curves: a nonparametric approach. Biometrics. 1988:44:837-45.

20. Dellinger RP, Levy MM, Rhodes A, Annane D, Gerlach H, Opal SM, et al. Surviving sepsis campaign: international guidelines for management of severe sepsis and septic shock, 2012. Intensive Care Med. 2013;39:165-228.

21. Zampieri FG, Damiani LP, Bakker J, Ospina-Tascón GA, Castro R, Cavalcanti $A B$, et al. Effects of a resuscitation strategy targeting peripheral perfusion status versus serum lactate levels among patients with septic shock. A Bayesian reanalysis of the ANDROMEDA-SHOCK Trial. Am J Respir Crit Care Med. 2020;201:423-9.

22. Madsen MB, Skrede S, Perner A, Arnell P, Nekludov M, Bruun T, et al. Patient's characteristics and outcomes in necrotising soft-tissue infections: results from a Scandinavian, multicentre, prospective cohort study. Intensive Care Med. 2019:45:1241-51.

23. James JH, Luchette FA, McCarter FD, Fischer JE. Lactate is an unreliable indicator of tissue hypoxia in injury or sepsis. Lancet. 1999;354:505-8.

24. Aduen J, Bernstein WK, Khastgir T, Miller J, Kerzner R, Bhatiani A, et al. The use and clinical importance of a substrate-specific electrode for rapid determination of blood lactate concentrations. JAMA. 1994;272:1678-85.

\section{Publisher's Note}

Springer Nature remains neutral with regard to jurisdictional claims in published maps and institutional affiliations.

Ready to submit your research? Choose BMC and benefit from:

- fast, convenient online submission

- thorough peer review by experienced researchers in your field

- rapid publication on acceptance

- support for research data, including large and complex data types

- gold Open Access which fosters wider collaboration and increased citations

- maximum visibility for your research: over $100 \mathrm{M}$ website views per year

At BMC, research is always in progress.

Learn more biomedcentral.com/submissions 